\title{
Erroneous Arctic Temperature Trends in the ERA-40 Reanalysis: A Closer Look
}

\author{
JAMES A. SCREEN AND IAN SIMMONDS \\ School of Earth Sciences, University of Melbourne, Melbourne, Victoria, Australia
}

(Manuscript received 7 September 2010, in final form 31 October 2010)

\begin{abstract}
Atmospheric reanalyses can be useful tools for examining climate variability and change; however, they must be used cautiously because of time-varying biases that can induce artificial trends. This study explicitly documents a discontinuity in the 40-yr European Centre for Medium-Range Weather Forecasts (ECMWF) Re-Analysis (ERA-40) that leads to significantly exaggerated warming in the Arctic mid- to lower troposphere, and demonstrates that the continuing use of ERA-40 to study Arctic temperature trends is problematic. The discontinuity occurs in 1997 in response to refined processing of satellite radiances prior to their assimilation into the reanalysis model. It is clearly apparent in comparisons of ERA-40 output against satellite-derived air temperatures, in situ observations, and alternative reanalyses. Decadal or multidecadal Arctic temperature trends calculated over periods that include 1997 are highly inaccurate, particularly below $600 \mathrm{hPa}$. It is shown that ERA-40 is poorly suited to studying Arctic temperature trends and their vertical profile, and conclusions based upon them must be viewed with extreme caution. Consequently, its future use for this purpose is discouraged. In the context of the wider scientific debate on the suitability of reanalyses for trend analyses, the results show that a series of alternative reanalyses are in broad-scale agreement with observations. Thus, the authors encourage their discerning use instead of ERA-40 for examining Arctic climate change while also reaffirming the importance of verifying reanalyses with observations whenever possible.
\end{abstract}

\section{Introduction}

Reanalyses are effectively weather analysis and forecasting systems run retrospectively. All available observations are assimilated into a dynamical global model of the atmosphere to provide an estimate of the atmospheric state at a particular time and location (Kalnay et al. 1996; Uppala et al. 2005). They are useful tools for examining climate variability and change because they provide greater spatial and temporal resolution than observations alone, combine information from a diverse range of sources, and adjust for biases that may exist in any specific observation type (Dee and Uppala 2009). They are arguably our best representation of the four-dimensional structure of the global atmosphere. However, they are not without their problems. A major concern with the use of reanalyses to study climate change is that the quantity and quality of observations

Corresponding author address: James Screen, School of Earth Sciences, University of Melbourne, Melbourne VIC 3010, Australia.

E-mail: screenj@unimelb.edu.au being assimilated into reanalysis models have changed over time (e.g., Bengtsson et al. 2004; Sterl 2004; Thorne and Vose 2010). This time-varying mix of observations can result in discontinuities in the reanalyses and induce artificial trends. Care especially needs to be taken when using reanalyses in the polar regions, where continuous long-term observations are particularly sparse (e.g., Sterl 2004; Bromwich et al. 2007).

One specific problem that has been identified in the 40-yr European Centre for Medium-Range Weather Forecasts (ECMWF) Re-Analysis (ERA-40) product is a shift of temperature bias in 1997. The ECMWF Web site (www.ecmwf.int/research/era/Data_Services/section3. html) states that

a problem of concern is cold bias in the lower troposphere (below about $500 \mathrm{hPa}$ ) over the ice-covered oceans in both the Arctic and the Antarctic ... These polar cold biases arise from the assimilation of HIRS [High Resolution Infrared Radiation Sounder] radiances. Changes to the thinning, channel-selection and quality control of the infrared data that were introduced for analyses from 1997 onwards to reduce tropical precipitation bias have also virtually eliminated the cold polar biases. 
The lower-tropospheric cold bias in ERA-40 was first documented by Bromwich et al. (2002). Its elimination in 1997 is mentioned by Bromwich and Wang (2005) and is discussed in more detail by Bromwich et al. (2007). The problem is specifically mentioned in the ERA-40 documentation (Uppala et al. 2005). However, despite this "known" shortcoming, ERA-40 has been recently used to assess Arctic temperature trends and their vertical structure. Most notably, ERA-40 formed the basis of a now-controversial examination of central Arctic temperature trends by Graversen et al. (2008). The results of that study have been strongly contested, mainly because of concerns about the accuracy of trends calculated from ERA-40 temperatures (Bitz and Fu 2008; Grant et al. 2008; Thorne 2008; Screen and Simmonds 2010b). Yet, ERA-40 continues to be used for Arctic temperature trend analysis (e.g., Yang et al. 2010). In light of this, we show here-explicitly and more thoroughly than previous studies - that inhomogeneities in ERA-40 lead to a poor representation of Arctic temperature trends, particularly in the mid- to lower troposphere, and we demonstrate that its continued use for this purpose is problematic.

\section{Data and methods}

We have assessed the performance of ERA-40 (Uppala et al. 2005) in the Arctic against multiple reference datasets: satellite data, radiosondes, and other reanalyses. The satellite data were temperature estimates from the Microwave Sounding Unit (MSU), processed independently by Remote Sensing Systems (RSS; Mears et al. 2003). Rather than measure air temperature at a particular height in the atmosphere, the MSU records the radiation emitted by a deep layer of the atmosphere that is then converted to a temperature estimate for that layer. Here we use MSU channels corresponding to two layers, one with greatest loading in the lower troposphere (TLT) and one with greatest loading in the midtroposphere (TMT) (Fig. 1e). To compare reanalysis data, archived on pressure levels, with the MSU data, the reanalysis temperature fields were vertically weighted by the MSU weighting functions (see, e.g., Spencer and Christy 1992; Basist and Chelliah 1997) and then averaged over all levels. We considered annual-mean and Arctic-mean temperatures calculated by averaging data north of $70^{\circ} \mathrm{N}$.

The radiosonde data were taken from the Met Office Hadley Centre Atmospheric Temperature version 2 (HadAT2) analysis (Thorne et al. 2005) for all meteorological stations north of $70^{\circ} \mathrm{N}$ that had near-complete records over the period 1979-2009. The nine selected stations [see supplementary Fig. 1 of Screen and Simmonds (2010b)] were then averaged. For comparison, the reanalyses were subsampled at the times and locations of available observations and averaged across all subsampled grid boxes. In what follows, we focus on annualmean data from levels 500 and $700 \mathrm{hPa}$. Comparisons between ERA-40 and radiosondes at all tropospheric levels, and by season, were provided in Screen and Simmonds (2010b).

We have also compared ERA-40 against the newer ECMWF ERA-Interim reanalysis (Simmons et al. 2007), the National Centers for Environmental PredictionNational Center for Atmospheric Research (NCEPNCAR) 40-Year Reanalysis (NNR; Kalnay et al. 1996), and the 25-yr Japanese Re-Analysis (JRA; Onogi et al. 2007).

\section{Comparisons with satellite data}

Figure 1a compares the time-varying biases in four different reanalyses relative to channel TLT of the MSU (note that we have removed the mean bias for each reanalysis to highlight the time-varying component of the bias). Generally, the biases fluctuate by up to $0.3^{\circ} \mathrm{C}$ and display no obvious discontinuities, with the exception of ERA-40, which displays a large jump in 1997. To assess the impact of this discontinuity on trends calculated from ERA-40, we computed 11-yr trends centered on each year between 1984 (1979-89) and 1996 (19912001). The ERA-40 trends largely fall within the $95 \%$ confidence intervals of the MSU TLT trends (Fig. 1b). However, ERA-40 significantly overestimates the warming for the trends centered on 1995 (1990-2000) and 1996 (1991-2001). ERA-40 also significantly exaggerates warming over the period 1979-2001, by more than a factor of 2 compared to the MSU (Table 1). The other three reanalyses depict decadal (Fig. 1b) and multidecadal (Table 1) trends within the $95 \%$ confidence intervals of the MSU trends.

Figure 1c compares the biases relative to MSU channel TMT, which has maximum loading higher in the troposphere than TLT (Fig. 1e). The discontinuity in ERA-40 is less pronounced, but still evident, in the midtroposphere. Likewise, the 11-yr trends centered on the mid-1990s are still exaggerated in ERA-40 compared to the MSU TMT; however, the differences are not statistically significant (Fig. 1d). ERA-Interim, NNR, and JRA all depict decadal (Fig. 1d) and multidecadal (Table 1) trends that are not statistically different from the MSU. Yang et al. (2010) show a plot similar to Fig. 1d and conclude that ERA-40 depicts realistic decadal-scale variability, despite unrealistic multidecadal variability (Bitz and Fu 2008; Grant et al. 2008; Thorne 2008; Screen and Simmonds 2010b). Our results demonstrate that this 
a) Bias relative to MSU TLT

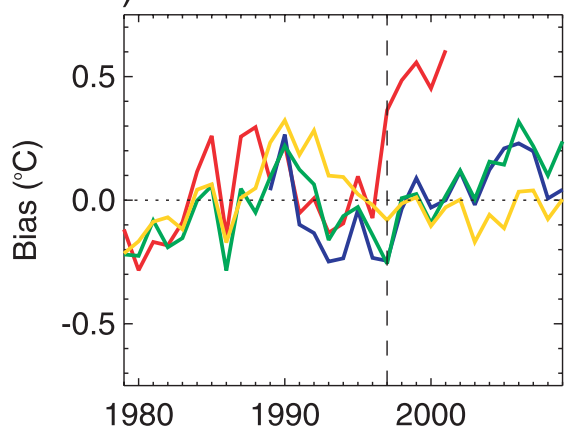

c) Bias relative to MSU TMT

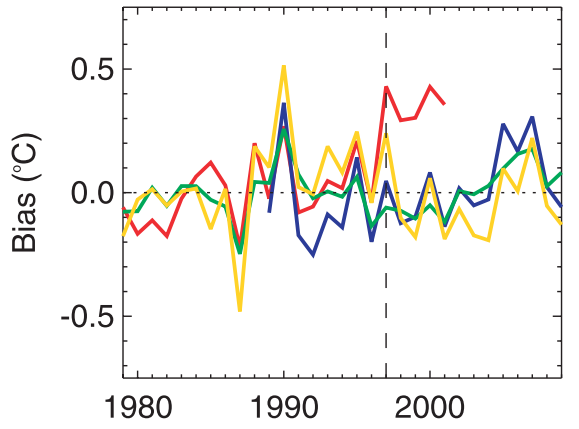

e) MSU weighting functions

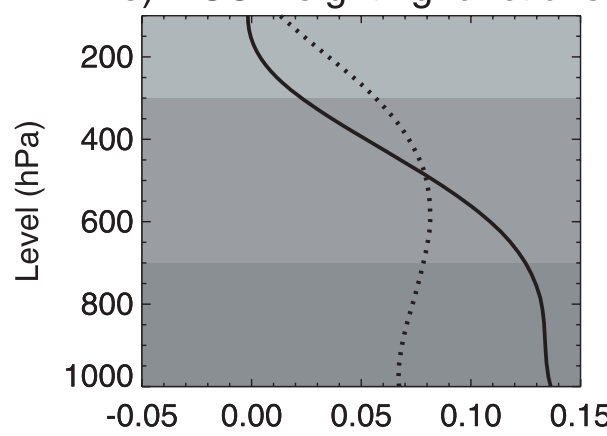

b) Decadal trends



d) Decadal trends
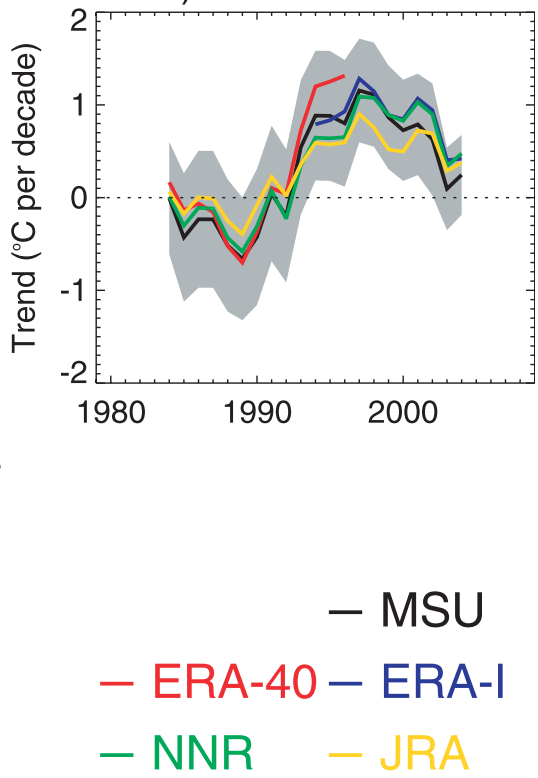

FIG. 1. (a) Arctic- and annual-mean temperature bias in each reanalysis relative to the MSU TLT. The reanalysis temperature fields were first vertically weighted by the MSU weighting function and then averaged over all vertical levels. For each reanalysis, the mean bias was removed to highlight the time-varying component of the bias. (b) Decadal Arctic- and annual-mean temperature trends from the MSU TLT and the reanalysis equivalents. Trends are centered on the indicated year (e.g., the trend at 1995 is based on data from 1990 to 2000). The gray band denotes the $95 \%$ confidence intervals of the MSU trends. (c) As in (a), but for biases relative to MSU TMT. (d) As in (b), but for trends in MSU TMT and the reanalysis equivalents. (e) Weighting functions for the MSU TLT (solid) and TMT (dashed) data. The gray shading denotes the lower-, mid-, and upper-troposphere classifications used in the text.

is not a valid conclusion, because realistic trends averaged over one vertical range do not imply that the trends are realistic at all levels.

\section{Comparisons with radiosondes}

We note that the MSU data may itself contain spurious trends because of merging different satellite records, orbital drift, and stratospheric influences (Hurrell and Trenberth 1997; Wentz and Schabel 1998; Fu et al. 2004). Therefore, we have also performed comparisons using radiosonde data, which are completely independent from the MSU data. Figure 2a shows biases in the reanalyses compared to $700-\mathrm{hPa}$ temperatures from radiosondes. These in situ data confirm that ERA-40 displays a shift in bias in 1997 and exaggerated warming in the mid-1990s (Fig. 2b). In contrast, the other three reanalyses display 
TABLE 1. Multidecadal annual-mean temperature trends $\left({ }^{\circ} \mathrm{C}\right.$ decade $\left.^{-1}\right)$ from the MSU and reanalysis equivalents. The top section corresponds to the MSU TLT and the lower section to the MSU TMT. The number in bold is significantly different from the MSU trend at the $95 \%$ confidence level.

\begin{tabular}{lccc}
\hline \hline & $1979-2009$ & $1979-2001$ & 1989-2009 \\
\hline MSU TLT & $0.37 \pm 0.13$ & $0.21 \pm 0.20$ & $0.66 \pm 0.20$ \\
ERA-40 & - & $\mathbf{0 . 4 7}$ & - \\
ERA-Interim & - & - & 0.77 \\
NNR & 0.47 & 0.26 & 0.75 \\
JRA & 0.37 & 0.26 & 0.51 \\
MSU TMT & $0.29 \pm 0.15$ & $0.12 \pm 0.24$ & $0.64 \pm 0.22$ \\
ERA-40 & - & 0.33 & - \\
ERA-Interim & - & - & 0.72 \\
NNR & 0.32 & 0.11 & 0.65 \\
JRA & 0.29 & 0.16 & 0.51 \\
\hline
\end{tabular}

more stationary biases and more realistic temperature evolution. The ERA-40 discontinuity is not seen at $500 \mathrm{hPa}$ (Fig. 2c), and the decadal trends fall within the $95 \%$ confidence bounds of the radiosonde data (Fig. 2d). Both NNR and JRA exhibit a downward drift in their temperature biases (Fig. 2c) that contribute to cooling in the late 1980s and early 1990s, whereas the radiosondes suggest modest warming (Fig. 2d).

\section{Comparisons with ERA-Interim}

To explore further the vertical extent of errors in ERA-40, we have calculated differences between ERA-40 and ERA-Interim during their overlapping period, 1989-2001. For decadal trends centered on the mid-1990s, of the four reanalyses examined, ERA-40 has the most unrealistic and ERA-Interim the most realistic trends compared to the MSU (Fig. 1). Figure 3a shows the differences (ERA-40 minus ERA-Interim) in Arctic- and annual-mean temperature as a function of height and year. In general, ERA-40 is colder than ERA-Interim in the Arctic, which likely reflects the cold bias reported by the ECMWF. However, a large discontinuity is once again apparent in 1997: the cold bias abruptly shifts to a weak warm bias. This shift is found at all levels below about $600 \mathrm{hPa}$. Shifts of temperature bias in 1997 are apparent in each season, but they are

a) Bias relative to radiosondes
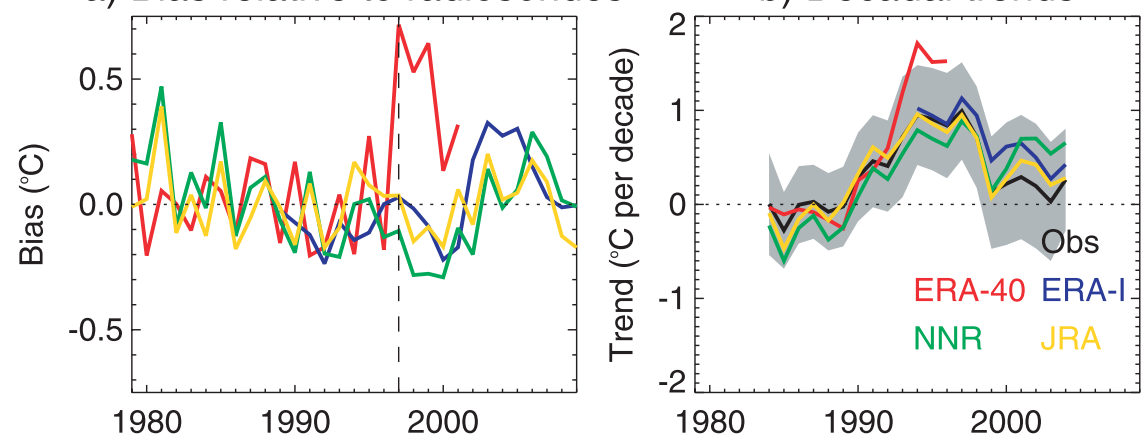

c) Bias relative to radiosondes

d) Decadal trends
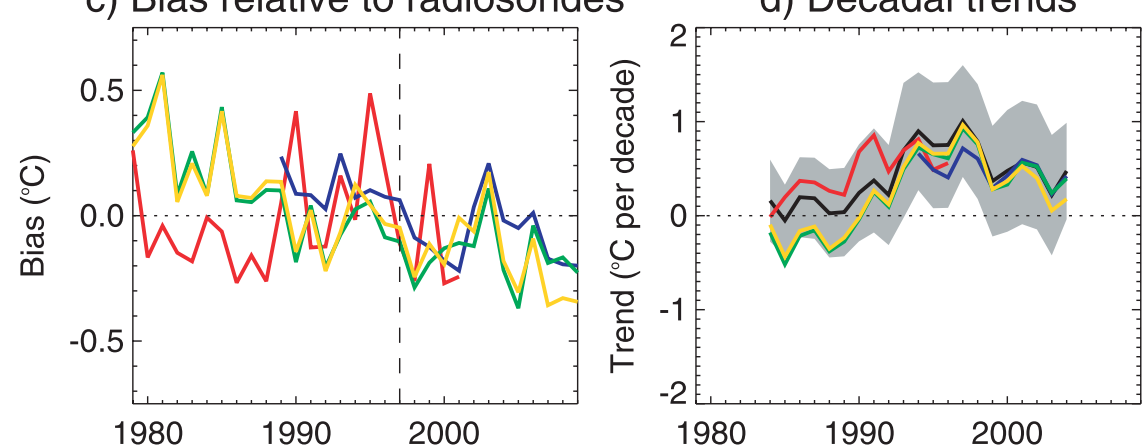

FIG. 2. (a) Arctic- and annual-mean 700-hPa temperature bias in each reanalysis relative to radiosondes. The radiosonde data are averages from nine Arctic stations. The reanalysis temperature fields were first subsampled at the station locations and then averaged over all subsampled grid boxes. For each reanalysis, the mean bias was removed to highlight the timevarying component of the bias. (b) Decadal Arctic- and annual-mean temperature trends from radiosondes and each reanalysis. Trends and gray band as in Fig. 1b. (c) As in (a), but for $500-\mathrm{hPa}$ temperature bias. (d) As in (b), but for 500-hPa temperature trends. 


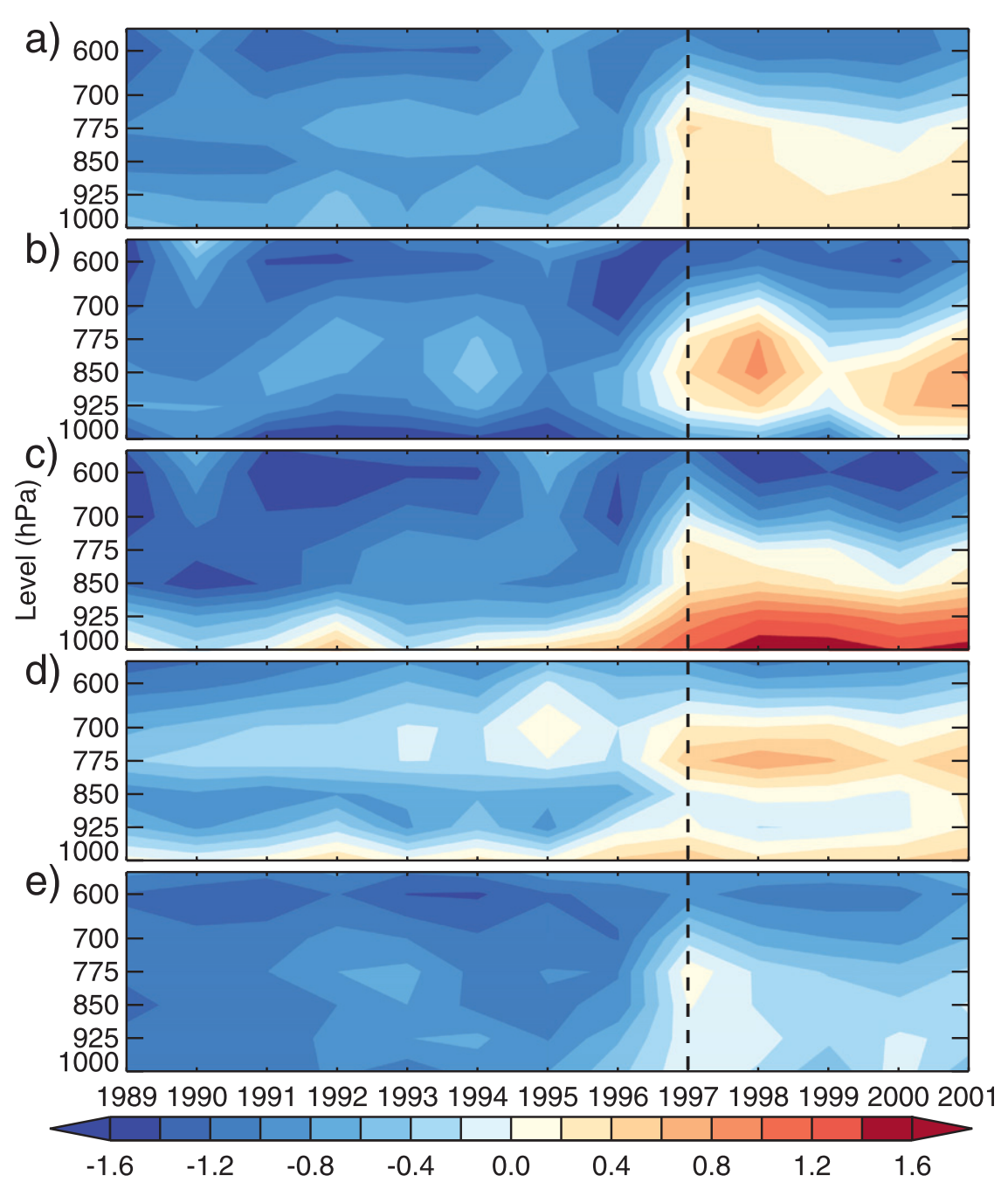

FIG. 3. (a) Arctic- and annual-mean temperature differences $\left({ }^{\circ} \mathrm{C}\right)$ between ERA-40 and ERA-Interim as a function of year and height. Blue (red) shading indicates that ERA-40 is colder (warmer) than ERA-Interim. (b)-(e) As in (a), but for winter [December-February (DJF)], spring [March-May (MAM)], summer [June-August (JJA)], and fall [SeptemberNovember (SON)].

most pronounced in winter and spring (Figs. 3b-e). As a consequence of this discontinuity, ERA-40 displays exaggerated annual- and seasonal-mean warming trends compared to ERA-Interim in the mid- to lower troposphere (Fig. 4). In general, the trend differences are statistically significant at latitudes north of approximately $60^{\circ} \mathrm{N}$ and at levels $700-1000 \mathrm{hPa}$. By season, the largest differences (up to $2.5^{\circ} \mathrm{C}$ decade $^{-1}$ ) are in winter and spring, with smaller (up to $1.5^{\circ} \mathrm{C}$ decade $^{-1}$ ), but still statistically significant, differences in summer and fall. Above $600 \mathrm{hPa}$, the temperature differences are relatively constant in time (Fig. 3) and the trend differences are small and nonsignificant in the Arctic (Fig. 4). This helps explain why ERA-40 depicts reasonably realistic trends compared to the MSU TMT but unrealistic trends compared to MSU TLT (cf. Fig. 4 to the MSU weighting functions in Fig. 1e). The seasonal and vertical structures of the trend differences do not match those of the observed temperature trends (Screen and Simmonds 2010a,b), implying that the ERA-40 errors do not simply influence the magnitudes of the trends but also lead to a rather different spatiotemporal pattern of temperature change from that observed.

Finally, we consider which regions of the Arctic are most affected by the ERA-40 problem. Figure 5 shows spatial maps of the annual- and seasonal-mean lowertropospheric $(700-1000 \mathrm{hPa})$ temperature trend differences between ERA-40 and ERA-Interim. In each season and in the annual mean, warming is exaggerated in ERA-40 most over the ice-covered Arctic Ocean. 

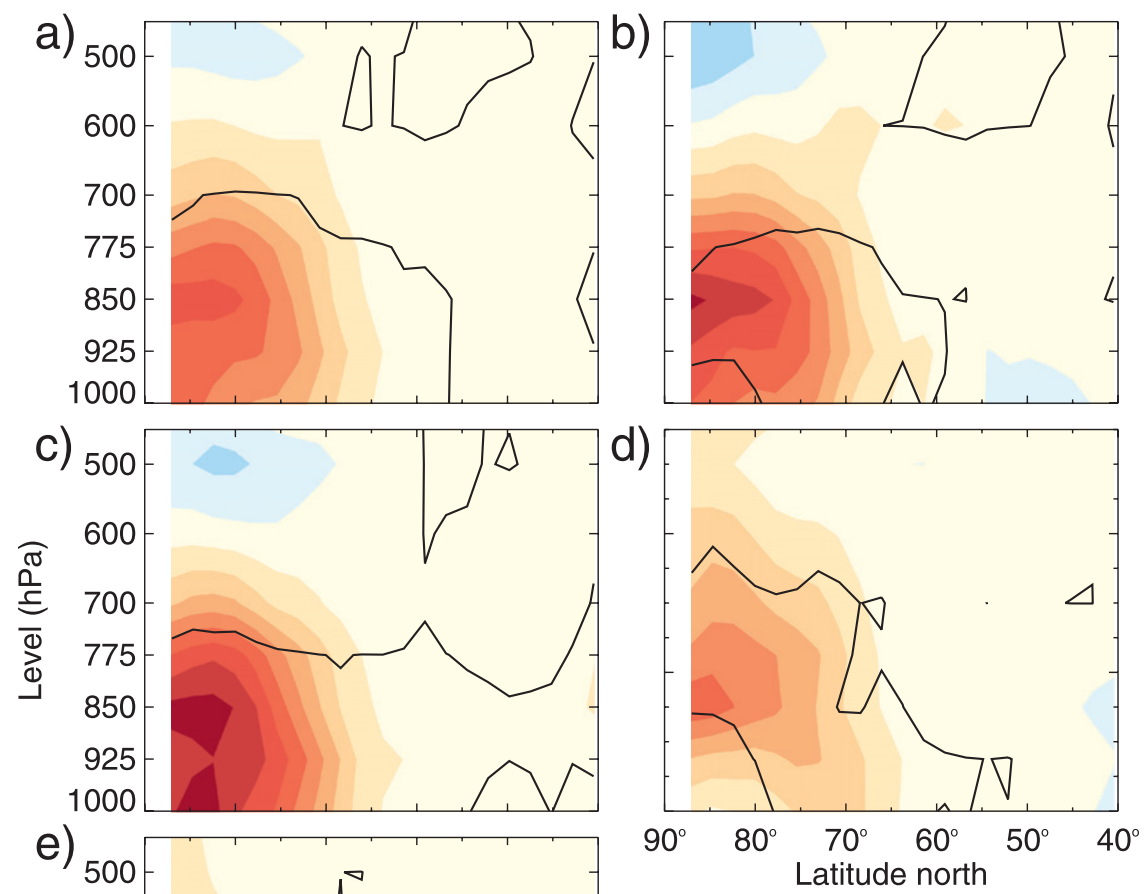

e)
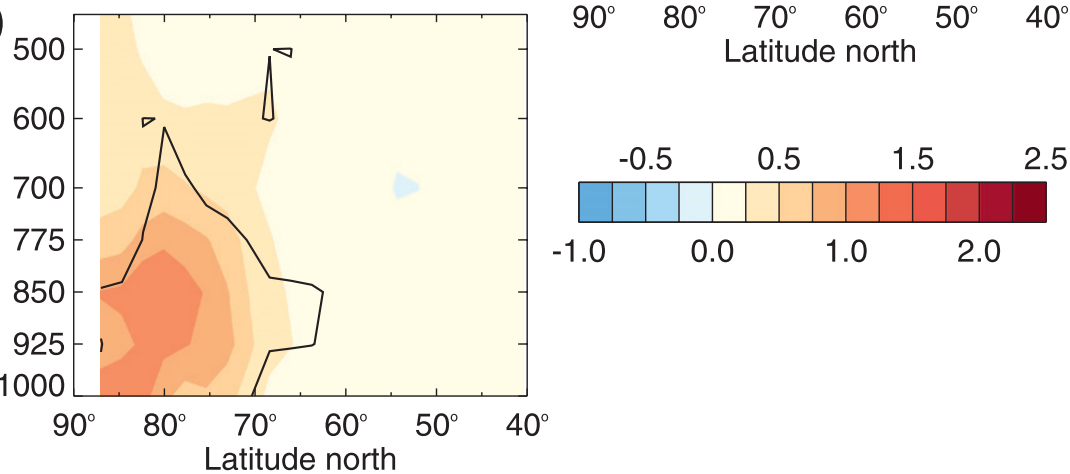

FIG. 4. (a) Annual-mean temperature trend differences $\left({ }^{\circ} \mathrm{C}\right.$ decade $\left.{ }^{-1}\right)$ between ERA-40 and ERA-Interim as a function of latitude and height. Red (blue) shading indicates larger (weaker) warming in ERA-40 than ERA-Interim over the period 1989-2001. The black contour denotes the $99 \%$ significance level. (b)-(e) As in (a), but for DJF, MAM, JJA, and SON.

Again, it is clear that the winter and spring temperature trends are the most affected. The trend differences over the land regions are smaller than over the ocean and are similar in magnitude between the seasons. The discrepancies are small over Alaska, northern Canada, and Scandinavia (generally less than $0.5^{\circ} \mathrm{C}$ decade $^{-1}$ ) and modest (up to around $1.0^{\circ} \mathrm{C}$ decade ${ }^{-1}$ ) over coastal Siberia. Warming over central Greenland is greater in ERA-40, particularly in summer and fall.

\section{Discussion and conclusions}

Our results clearly demonstrate that ERA-40 depicts unrealistic temperature trends in the Arctic mid- to lower troposphere due to an artificial temperature shift in 1997. Decadal or multidecadal temperature trends calculated over periods that include 1997 are inaccurate, particularly below $600 \mathrm{hPa}$. Although we have focused on temperature trends, we urge caution when using ERA-40 to examine all aspects of Arctic atmospheric change, as other related parameters may also exhibit large discontinuities.

We stress that it is not our intention to evaluate the conclusions of all the numerous studies that have used ERA-40 in the Arctic, many of which likely were, and remain, valid. However, here we briefly mention two examples to help illustrate our concerns with ERA-40 temperature trends and the conclusions derived from them. To be clear, these examples are used because they neatly demonstrate weaknesses with ERA-40 and not because their conclusions are necessarily the most questionable. In the case of Yang et al. (2010), their analysis of TMT trends was undertaken with MSU, ERA-40, 

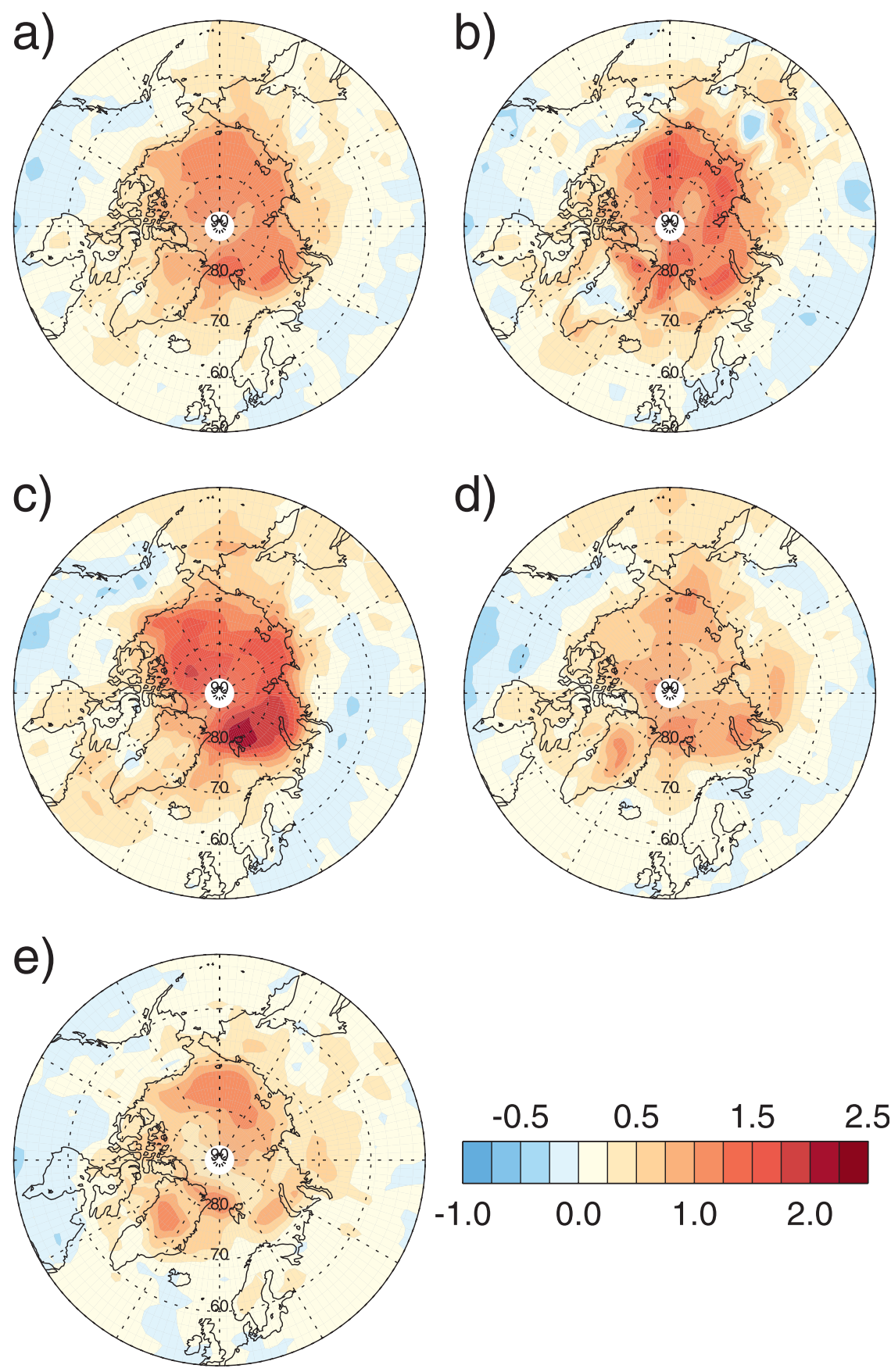

FIG. 5. (a) Annual-mean lower-tropospheric (700-1000 hPa) temperature trend differences $\left({ }^{\circ} \mathrm{C}\right.$ decade $\left.{ }^{-1}\right)$ between ERA-40 and ERA-Interim. Shading as in Fig. 4a. (b)-(e) As in (a), but for DJF, MAM, JJA, and SON.

and NNR data-all of which were in broad agreement. We also find agreement between datasets for the TMT trends (Fig. 1) and therefore have no reason to question the validity of their results pertaining to the evolution of TMT temperature. However, their analysis becomes problematic when only ERA-40 is used examine the vertical profile of temperature trends. We have shown that a realistic depiction of TMT trends does not imply realistic trends in the lower troposphere or a realistic vertical profile. Yang et al. examined the vertical structure of temperature trends over two periods: $1984-94$ and 1991-2001. Based on our analyses above, we expect the 
trends in the mid- to lower troposphere to be unrealistic in the latter period, as it includes the 1997 discontinuity. In the case of Graversen et al. (2008), who used the vertical profile of temperature trends as a fingerprint to explore the causes of Arctic temperature amplification, errors in ERA-40 led to exaggerated warming aloft and a fundamentally different warming profile from that in observations or alternative reanalyses (Bitz and Fu 2008; Grant et al. 2008; Thorne 2008; Screen and Simmonds 2010a,b).

While our results reiterate problems with using reanalyses to examine trends (Bengtsson et al. 2004; Sterl 2004; Thorne and Vose 2010), they do not imply that all reanalyses are unsuitable for studying Arctic temperature trends and their vertical structure. Indeed, we have shown that ERA-40 is unique among a series of alternative reanalyses in displaying statistically significant errors. We conclude that with the exception of ERA-40, current reanalyses are in broad-scale agreement with observed Arctic temperature change and encourage their discerning use instead of ERA-40, and in conjunction with observations where possible.

Acknowledgments. We are grateful to the ECMWF, NCEP-NCAR, Japan Meteorological Agency, RSS, and Met Office Hadley Centre for making their respective datasets readily available online. We thank the three anonymous reviewers for their comments. Parts of this research were funded by the Australian Research Council.

\section{REFERENCES}

Basist, A. N., and M. Chelliah, 1997: Comparison of tropospheric temperatures derived from the NCEP/NCAR reanalysis, NCEP operational analysis, and the Microwave Sounding Unit. Bull. Amer. Meteor. Soc., 78, 1431-1447.

Bengtsson, L., S. Hagemann, and K. I. Hodges, 2004: Can climate trends be calculated from reanalysis data? J. Geophys. Res., 109, D11111, doi:10.1029/2004JD004536.

Bitz, C. M., and Q. Fu, 2008: Arctic warming aloft is data set dependent. Nature, 455, E3-E4, doi:10.1038/nature07258.

Bromwich, D. H., and S.-H. Wang, 2005: Evaluation of the NCEPNCAR and ECMWF 15- and 40-yr reanalyses using rawinsonde data from two independent Arctic field experiments. Mon. Wea. Rev., 133, 3562-3578.

,-- , and A. J. Monaghan, 2002: ERA-40 representation of the Arctic atmospheric moisture budget. ECMWF workshop on reanalysis, ECMWF Re-Analysis Project Rep. Series 3, 287-298.

_, R. Fogt, K. I. Hodges, and J. E. Walsh, 2007: A tropospheric assessment of the ERA-40, NCEP, and JRA-25 global reanalyses in the polar regions. J. Geophys. Res., 112, D10111, doi:10.1029/2006JD007859.

Dee, D. P., and S. Uppala, 2009: Variational bias correction of satellite radiance data in the ERA-Interim reanalysis. Quart. J. Roy. Meteor. Soc., 135, 1830-1841.

Fu, Q., C. M. Johanson, S. G. Warren, and D. J. Seidel, 2004: Contribution of stratospheric cooling to satellite-inferred tropospheric temperature trends. Nature, 429, 55-58.

Grant, A. N., S. Brönnimann, and L. Haimberger, 2008: Recent Arctic warming vertical structure contested. Nature, 455, E2-E3, doi:10.1038/nature07257.

Graversen, R. G., T. Mauritsen, M. Tjernström, E. Källén, and G. Svensson, 2008: Vertical structure of recent Arctic warming. Nature, 451, 53-56.

Hurrell, J. W., and K. E. Trenberth, 1997: Spurious trends in satellite MSU temperature from merging different satellite records. Nature, 385, 164-167.

Kalnay, E., and Coauthors, 1996: The NCEP/NCAR 40-Year Reanalysis Project. Bull. Amer. Meteor. Soc., 77, 437-471.

Mears, C. A., M. C. Schabel, and F. J. Wentz, 2003: A reanalysis of the MSU channel 2 tropospheric temperature record. J. Climate, 16, 3650-3664.

Onogi, K., and Coauthors, 2007: The JRA-25 Reanalysis. J. Meteor. Soc. Japan, 85, 369-432.

Screen, J. A., and I. Simmonds, 2010a: Increasing fall-winter energy loss from the Arctic Ocean and its role in Arctic temperature amplification. Geophys. Res. Lett., 37, L16707, doi:10.1029/ 2010 GL044136.

, and $-2010 \mathrm{~b}$ : The central role of diminishing sea ice in recent Arctic temperature amplification. Nature, 464, 1334-1337.

Simmons, A., S. Uppala, D. P. Dee, and S. Kobayashi, 2007: ERA-Interim: New ECMWF reanalysis products from 1989 onwards. ECMWF Newsletter, No. 110, ECMWF, Reading, United Kingdom, 25-35.

Spencer, R. W., and J. R. Christy, 1992: Precision and radiosonde validation of satellite gridpoint temperature anomalies. Part I: MSU channel 2. J. Climate, 5, 847-857.

Sterl, A., 2004: On the (in)homogeneity of reanalysis products. J. Climate, 17, 3866-3873.

Thorne, P. W., 2008: Arctic tropospheric warming amplification? Nature, 455, E1-E2, doi:10.1038/nature07256.

— long-term trends: Are they really achievable? Bull. Amer. Meteor. Soc., 91, 353-361.

- D. E. Parker, S. F. B. Tett, P. D. Jones, M. McCarthy, H. Coleman, and P. Brohan, 2005: Revisiting radiosonde upper air temperatures from 1958 to 2002. J. Geophys. Res., 109, D18105, doi:10.1029/2004JD005753.

Uppala, S. M., and Coauthors, 2005: The ERA-40 Re-Analysis. Quart. J. Roy. Meteor. Soc., 131, 2961-3012.

Wentz, F. J., and M. C. Schabel, 1998: Effects of satellite orbital decay on MSU lower tropospheric temperature trends. $\mathrm{Na}$ ture, 394, 661-664.

Yang, X.-Y., J. C. Fyfe, and G. M. Flato, 2010: The role of poleward energy transport in Arctic temperature evolution. Geophys. Res. Lett., 37, L14803, doi:10.1029/2010GL043934. 